\title{
DESIGN OF AN EARTHQUAKE RESISTING BUILDING USING PRECAST CONCRETE CROSS-BRACED PANELS AND INCORPORATING ENERGY ABSORBING DEVICES
}

\author{
C.D. Matthewson* and R.A. Davey **
}

\section{ABSTRACT}

The design and the analysis of an irregular six storey office building are described. The building has an unconventional earthquake resisting system: a precast concrete cross-braced perimeter frame incorporating forcelimiting devices (termed "inserts") in the form of enclosed axially yielding short steel members.

A series of inelastic dynamic analyses indicates that the system very effectively combines the inherent strength and stiffness of the cross-braced frame with the energy-dissipating function of the yielding inserts.

Cost estimates indicate that the system is a particularly economic one.

\section{INTRODUCTION}

This paper describes the earthquake resisting system used for a government office building to be constructed in Wanganui, New Zealand. The building is of $4120 \mathrm{~m}^{2}$ in six storeys and a basement. Site and aesthetic considerations dictated the shape of the building which is formed of $6 \mathrm{~m}$ square modules in an irregular plan form and with irregular set-backs at each storey. Further design constraints were introduced by the requirements of a short construction time and a strict cost ceiling.

The rigid lower ground floor structure has cast-in-place reinforced concrete perimeter walls and flat slab floor. The superstructure comprises reinforced concrete columns with precast concrete beams and floor. Earthquake resistance is provided by a stiff perimeter structure formed from precast concrete panels incorporating energy dissipating steel "inserts".

The extensive use of precasting should minimise construction time, and the steel inserts provide a controlled response to seismic excitation. The stiffness of the structure minimises the need for damage control detailing, and no separate "architectural" decoration is needed.

A view of the structure is given in figure 1.

\section{EARTHOUAKE RESISTING SYSTEM}

The perimeter structure comprises $5 \mathrm{~m}$ long $\mathrm{x}$ $3 \mathrm{~m}$ high precast concrete panels in a cross-braced form, with overturning forces at corners being carried by insitu reinforced concrete columns. Connections are made of welded steel later encased in reinforced concrete.

The structure is inherently very still and strong, and a large earthquake would produce very high forces in the connections and in the corner

* District Structural Engineer, Ministry of Works and Development, Wanganui.

** Senior Engineer, Ministry of Works and Development, Wanganui. columns. These forces are controlled by the introduction of steel insert assemblies to the bottom ends of the diagonal members in the lowest three storeys.

The central component of an assembly is a mild steel hollow section which yields axially at a given force level. This is separated from the surrounding concrete by a further hollow section, and there is a movement gap across the concrete brace. Preliminary details of the panels, inserts, and connections are given in section 5 .

Some beam and column frame action occurs in conjunction with the primary "truss" action of the structure. The relative stiffnesses are such that the frame action is not very significant while the building remains elastic. After yielding of the inserts, however, the frame structure performs a very significant function, which is later described.

A typical deflected shape of one cross-braced frame under seismic loading is shown in figure 2.

\section{STATIC DESIGN AND ANALYSIS}

Design of the primary yielding members, the steel inserts, was based on a static space frame analysis using the equivalent static force method of the New Zealand loadings code, NZS 4203(1) with a lateral force coefficient of 0.30 . This is twice the code-specified basic coefficient: the relatively high multiplier was chosen because of the unconventional nature of the structure, and to restrict ductility demand. Although calculated building eccentricities were very low, the nominal eccentricities required by the code meant that the design yield level for the structure under a direct code-distributed load was $0.36 \mathrm{~g}$.

Design of the connections between panels and columns allowed for potential overstrength of the inserts.

Column axial forces were calculated allowing for simultaneous yielding, at overstrength, of the inserts in both building axes and in all storeys. The columns were then designed for this axial load combined with twice the bending 
moment at first yield (including overstrength) of all the inserts. The purpose of this design procedure was that the columns remain elastic at a structure ductility factor of about two.

The maximum interstorey deflection computed in accordance with NZS 4203 was $3 \mathrm{~mm}$ - this includes a multiplier of 1.3 , to allow for the inelasticity associated with a moderate earthquake. Positive separation of windows is mandatory under the NZ Code at this level of deflection. It was considered that other non-structural elements could tolerate a drift of about $8 \mathrm{~mm}$ without damage $(2)$ and need not be separated.

\section{DYNAMIC ANALYSES}

\subsection{Analysis Technique}

Inelastic dynamic time history analyses were done on the Ministry of Works and Development IBM 370/168 computer using the DRAIN-2D program (3). The program allows analysis of two dimensional structures with bilinear member stiffnesses.

Basic assumptions made were:

(i) that the ratios of plastic to elastic stiffness are $1 \%$ for structural steel and $3 \%$ for reinforced concrete:

(ii) that damping is $5 \%$ of critical in each of the first two modes;

(iii) that reinforced concrete members retain a stiffness corresponding to the uncracked condition.

Sensitivity to each of these assumptions was tested within the series of analyses done.

Analyses were also done to facilitate final insert design, by comparing insert lengths of $0.7 \mathrm{~m}$ and $1.4 \mathrm{~m}$.

A time step of 0.01 seconds was used for all analyses.

The various earthquake records used were:

(i) El Centro $1940 \mathrm{~N}-\mathrm{S}$ component

(ii) $1.5 \mathrm{El}$ Centro

(iii) Artificial Al, first $10 \mathrm{sec}$

(iv) Artificial Bl, first $10 \mathrm{sec}$

(v) Parkfield $1966 \mathrm{~N} 65 \mathrm{E}$

The unscaled El Centro record is regarded as the basic design earthquake: this fits with the NZ loadings code and an earthquake of this magnitude would have an estimated return period of the order of 150 years in Wanganui. 1.5 El Centro and Al would probably approximate the maximum credible event, and Parkfield was included for interest, although not considered to be a relevant design earthquake for this site.

The irregularity of the building presented a problem with modelling because there is no typical frame. Linking of all the frames in one direction would provide an unmanageably large representation, so an equivalent single bay lumped model was formed by suming the individual beam, column, and diagonal member properties. This lumped model, representing the whole structure, is coupled to a particular frame for study of that frame. The model is shown in figure 3.

The assumptions involved in this model are: (i) that the column bending moment at yield in the lumped frame can be assumed to be constant - i.e. not affected by the axial load - without significant error;

(ii) that the lumping of beam and column bending stiffnesses produces insignificant error;

(iii) that the deflections are basically of the shear rather than bending type, i.e. column axial deformations are not significant and areas can be set artificially high in the lumped model.

Assumption (i) is reasonable - only in corner columns does the axial force vary with seismic load - and would be irrelevant if no columns were to yield. In fact, yielding was not detected in any of the particular frames studied.

Assumptions (ii) and (iii), were tested statically by comparing a 3 bay frame with its lumped model. Test analyses used both the elastic member properties and softened $(0.1$ original stiffness) diagonal braces to represent a post yield condition. Assumption (ii) produced a maximum deflection error of $0.2 \%$ for the softened model, which is clearly insignificant. Assumption (iii) produced a maximum error of $7 \%$ in the top deflection for the elastic condition, which reduced to $1.5 \%$ for the softened model. Dynamic analysis results can be expected to have an error of about $4 \%$ in the top deflection (with a lesser error at lower levels) and a correspondingly small error in response characteristics.

\subsection{Analysis Results}

Fourteen dynamic analyses were performed, which were designed both to test the sensitivity to analysis assumptions, and to assist design of the steel inserts.

The results of particular interest are:

(i) the required local ductility in the yielding steel inserts; and

(ii) the interstorey drifts.

Results are presented in table la, with a key to the parameter variations in table lb. The required ductilities may be judged in the light of a single preliminary compression test on a rectangular hollow section of similar size to that expected to be used, but with a thinner will section. This exhibited local crippling at a ductility factor of about 15. The interstorey drifts may be judged against the estimation that damage to partition walls, etc. will become significant above a value of about $8 \mathrm{~mm}$.

No column yielding was detected.

\subsection{Comments on analysis results}

All results show a steel insert ductility demand below the preliminary - and probably low estimate of the available level, and in all but for the Parkfield record it is less than half that level. The values for interstorey drift comply with the criterion of approximately $8 \mathrm{~mm}$, with the exceptions of those for the Parkfield record and those for an insert length of $1400 \mathrm{~mm}$. Consideration of the results has led to the adoption of $700 \mathrm{~mm}$ as the insert length, so the single remaining result which does not comply with the desirable design criteria is the interstorey drift under the Parkfield earthquake. Thus 


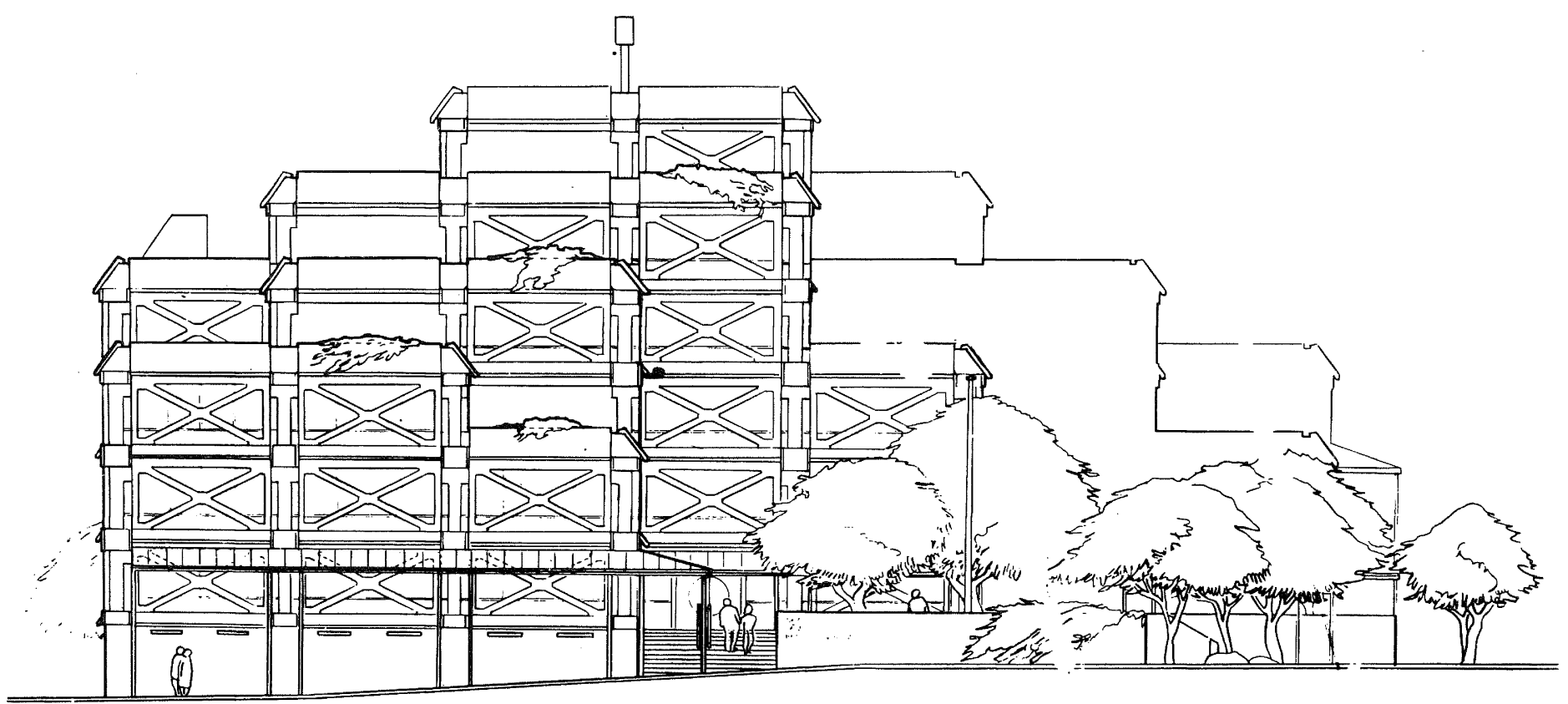



Figure 2. Typical deflected shape of typical wall under seismic load
Figure 1. Elevation of Building

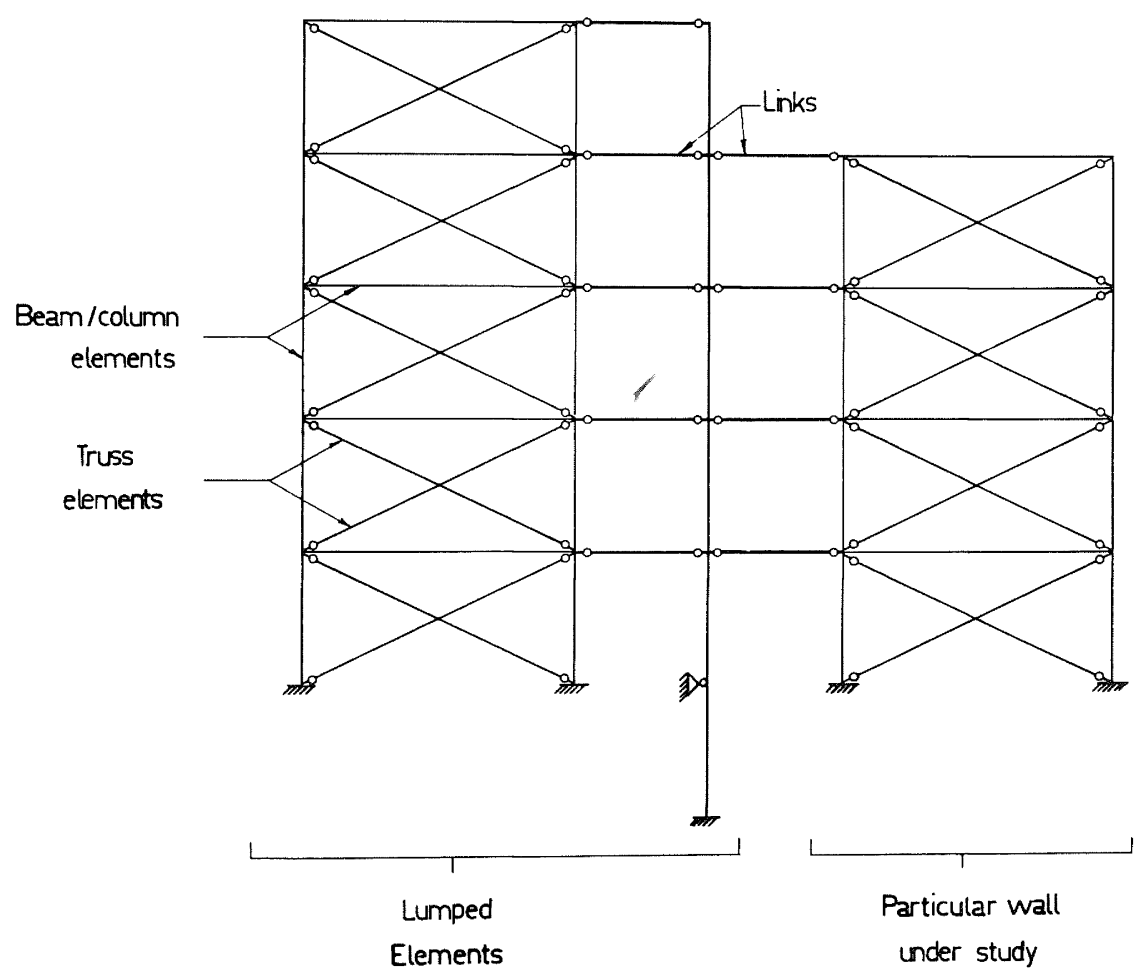

Figure 3. Dynamic Analysis Model 
the building can be expected to survive what has been taken as the maximum credible event, with little damage.

The analysis could consider only an earthquake attack parallel to one of the building axes. the case of the ductility demand on the insert this would give a maximum effect. In the case of some corner columns, however, a biaxial attack would produce a more severe effect and so a small amount of yielding might occur in isolated columns under this condition.

The structure does not appear to be sensitive enough to any of the assumed properties for these assumptions to affect general conclusions about behaviour. Generally, the effect of varying a parameter has been very much as expected.

One interesting feature is the effect of varying frame stiffness, because this gives a clue as to how the frame action relates to the dominant truss action. As previously stated, the frame elastic stiffness is small compared with the truss elastic stiffness (the ratio is about 15\%). However, the frame remains elastic after the steel inserts yield. This has the effect of providing a significant second slope on the load deflection curve for the whole structure. To test the importance of this effect a further run was done with the frame stiffness reduced to an artificially low 0.1 of the uncracked value. This gave, for El Centro, a maximm top displacement of $28 \mathrm{~mm}$, a maximum interstorey displacement of $16 \mathrm{~mm}$, and a steel insert ductility demand of 12 . This indicates that the frame structure, which carries little of the total shear and provides little of the initial stiffness, still performs a most significant function in limiting deflections and the ductility demand on the steel inserts. Physically, the elastic frame action provides a helpful additional restoring force while the inserts are yielding.

In addition, the reliable second slope provided by the frame ensures that the yielding is not confined to the lowest storey - a "soft storey" building. A further trial analysis with the yielding inserts in only the first storey confirmed the conclusion of Chopra et al (4) that the significant second slope produces high forces in upper storeys, as well as indicating confirmation of the "yield spreading" function of the frame.

The sensitivity to the "strain hardening ratio"the second slope of the steel insert load deflection curve - was low because this second slope is effectively superimposed on the above effect, and thus loses much of its own significance.

\section{PANEL DETAILS}

Preliminary details of the precast reinforced concrete wall panels are shown in figures 4 and 5. Separate steel plates are cast into the panels and into the columsn, and are butt welded together to transfer the vertical component of the diagonal forces. Inertia loads are introduced to the panels by connection of the floor slab diaphragms to the panel top chords.

The steel inserts in the panel diagonals are formed from mild steel rolled hollow sections. The steel will be stress relieved to maximise available ductility as the only obtainable sections are cold rolled. The yielding RHS is separated from the surrounding concrete by another RHS which gives approximately $2 \mathrm{~mm}$ clearance and will provide lateral restraint if necessary. Lateral translation of one end of an insert relative to the other is limited by a circumferential plate cut to a close tolerance fit and placed at the lower end of the diagonal. Inserts will be galvanised after fabrication.

A testing programme is to be undertaken to assure the proper functioning of the insert assemblies.

\section{BUILDING COSTS}

At the time of writing, working drawings of the building described are not complete, and a firm estimate of cost is not available. However, the preliminary estimate gives a structural and cladding cost about $25 \%$ less per square metre than for a 6 storey conventional reinforced concrete frame building of similar size and use recently completed in Wanganui.

\section{CONCLUSION}

The design presented here utilizes the advantages of precasting in an irregular medium rise seismic load resisting building. The effectiveness of incorporating energy dissipating devices within the structure has been demonstrated by a series of inelastic dynamic time history analyses and the details of the devices have been given.

The building should survive a major earthquake with little structural or non-structural damage, and preliminary costing indicates that the system is most economical.

\section{ACKNOWLEDGEMENTS}

The building described in this paper was designed in the Wanganui District Office of the New Zealand Ministry of Works and Development.

The authors wish to acknowledge a good working relationship with the job architect Mr A.D. Baker, and the helpful attitude of the MrD Chief Structural Engineer, Mr O.A. Glogau. Mr B.W. Buchanan, Senior Design Engineer, provided useful comments during the preparation of the paper.

\section{REFERENCES:}

1. NZS4203:1976 N.Z. Standard Code of Practice for General Structural Design and Design Loadings for Buildings.

2. M.J. Collins, "A Light Timber Frame Wall Bracing Test and Set of Performance Criteria", N.Z. Forest Service Reprint No. 942, 1975.

3. A.E. Kanaan and G.H. Powell, "DRAIN-2D, A General Purpose Computer Programme for Dynamic Analysis of Inelastic Plane Structures", Earthquake Engineering Research Centre, University of California, Berkeley, 1973.

4. A.K. Chopra, D.P. Clough, and R.W. Clough, "Earthquake Resistance of Buildings with a 'Soft' First Storey", Earthquake Engineering 




Figure 4. Precast concrete Wall Panel Details



Plate cut to give $1 \mathrm{~mm}$ max. $89 \times 89 \times 3.6$ R.H.S. Sleeve.

Figure 5. Steel Insert Details 
and Structural Dynamics, Vol. 1, pp 347-355, 1973.

A slightly modified version of this paper was presented at the South Pacific Regional Conference on Earthquake Engineering, Wellington, May 1979.

\section{ADDENDUM}

Working drawings have been completed since this paper was first presented, and the following further information is now available.

\section{(1) Insert Design}

The preliminary detail using a rectangular hollow section has been superseded. The insert is now formed from a thick walled mild steel circular hollow section, which can be machined to a thickness dependent on the measured yield strength. Heat treatment is no longer necessary, and the amount of welding is reduced. The revised assembly is shown in figure 6 .
(2) Insert Testing

An insert testing programme has been completed which demonstrated perfectly satisfactory

behaviour. Reversing strains of about 2.3\%

(representing a ductility factor of about 15) were applied which produced typical stable mild steel behaviour with no adverse effects due to either overall buckling or local crippling.

(3) Costs

The final estimate of cost has confirmed that the system should prove to be very competitive economically.

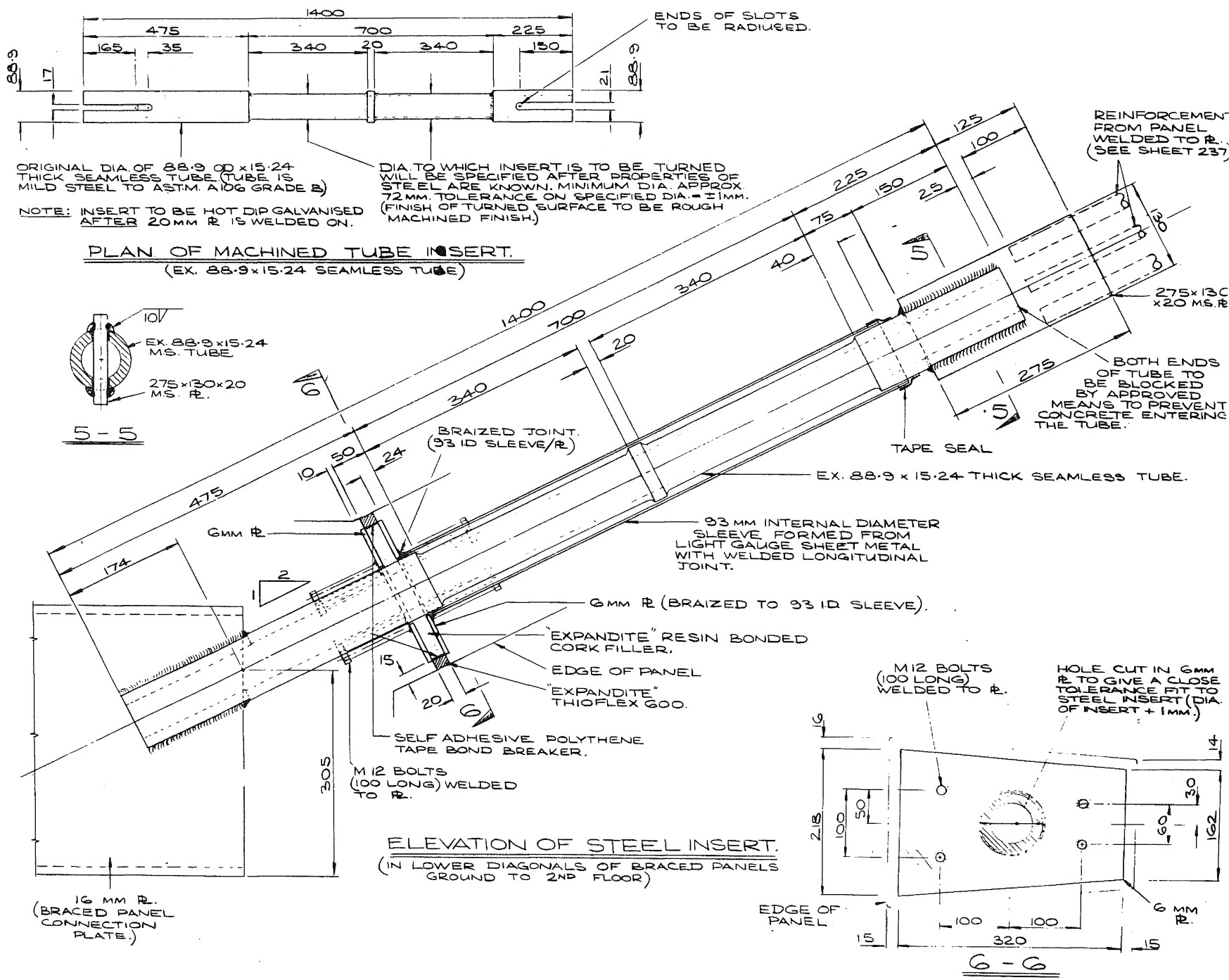

